\title{
A inserção do bibliotecário no mercado de trabalho sob a óptica dos fatores de influência
}

\author{
Ana Carolina Cintra Faria \\ Centro Universitário Desenvolvimento do Centro-Oeste (UNIDESC), Núcleo Interdisciplinar de Pesquisa, \\ Cidade Ocidental, Goiás, Brasil \\ anacarolina.cintrafaria@gmail.com \\ Maria Tereza Machado Teles Walter \\ Supremo Tribunal Federal, Biblioteca, Brasília, DF, Brasil \\ terezaw@gmail.com \\ Sofia Galvão Baptista \\ Universidade de Brasília, Faculdade de Ciência da Informação, Brasília, DF, Brasil \\ sofiag@unb.br
}

Resumo: O presente artigo apresenta parte dos resultados obtidos na dissertação de mestrado, realizada entre os anos de 2013 e 2015. O recorte aqui estabelecido investigou os fatores que influenciaram a inserção dos bibliotecários, egressos das universidades públicas da Região Sudeste, que oferecem os cursos na área da Biblioteconomia, no mercado de trabalho. A abordagem de pesquisa baseou-se no pilar dos fatores de influência para inserção do bibliotecário no mercado profissional. 0 interesse pela temática é advindo dos estudos que verificaram, no mercado de trabalho possível para os bibliotecários, amplas possibilidades de atuação e diversidade de tarefas. A delimitação destes mercados profissionais foi baseada na abordagem mercadológica proposta por Valentim $(2000,2002)$. Do ponto de vista metodológico, a pesquisa se caracteriza como sendo de ordem descritiva e exploratória, além de se utilizar da abordagem mista, uma vez que foram utilizados métodos qualitativos e quantitativos para tratamento dos dados. Ao final, foi possível constatar que na segunda década do século XXI se pode considerar pequeno o número dos bibliotecários que atuam em funções que não estão diretamente relacionadas ao ambiente das bibliotecas.

Palavras-Chave: Bibliotecário; Brasil - Região Sudeste; Fatores de influência; Mercado de trabalho.

The insertion of the librarian in the labor market from the perspective of influencing factors

Abstract: This article presents part of the results obtained in the dissertation, carried out between 2013 and 2015. The cut set forth herein investigated the factors that influenced the inclusion of librarians, graduates of public universities in the Southeast region of Brazil, offering courses in Librarianship in the labor market. The research approach was based on the pillar of influence factors for insertion of the librarian in the professional market. The interest for this subject raised from the studies that pointed out the broad possibilities of labor market for librarians, and the diversity of tasks. The delimitation of these professional markets was based on marketing approach proposed by Valentim (2000, 2002). From a methodological point of view, the research is characterized as descriptive and exploratory using the mixed approach of qualitative and quantitative methods for data processing. At the end, it was found that in the second decade of XXIth century it still can be considered small the number of librarians who work in tasks that are not directly related to libraries.

Keywords: Brazil - Southeast region; Influence factors; Labor market; Librarian. 
La inserción del bibliotecario en el mercado de trabajo bajo la óptica de los factores de influencia Resumen: El presente artículo presenta parte de los resultados obtenidos en la disertación de maestría, realizada entre los años de 2013 y 2015. El ambito establecido analizó los factores que influenciaron la inserción de los bibliotecarios, egresados de las universidades públicas de la Región Sudeste, que ofrecen los cursos en el área de la Bibliotecología, en el mercado de trabajo. El abordaje de la investigación se basó en los factores de influencia para inserción del bibliotecario en el mercado profesional. El interés por la temática es derivado de los estudios que verificaron, en el mercado de trabajo potencial para los bibliotecarios, amplias posibilidades de actuación y diversidad de tareas. La delimitación de estos mercados profesionales fue basada en el abordaje de marketing propuesto por Valentim $(2000,2002)$. Del punto de vista metodológico, la investigación se caracteriza por ser de tipo descriptiva y exploratoria, además de usar el abordaje mixto, toda vez que fueron utilizados métodos cualitativos y cuantitativos para el tratamiento de los datos. Al final, fue posible constatar que en la segunda década del siglo XXI se puede considerar el pequeño el número de los bibliotecarios que se desenpeñan en funciones que no están directamente relacionadas al ambiente de las bibliotecas.

Palabras clave: Bibliotecario; Brasil - Región Sudeste; Factor de influencia; Mercado de trabajo.

\section{Introdução}

Este artigo apresenta, de forma parcial, os resultados obtidos na pesquisa de mestrado realizada entre os anos de 2013 e 2015, cujo objetivo foi identificar os fatores que influenciaram a inserção dos bibliotecários, formados no período compreendido entre os anos de 2010 e 2014 nas universidades públicas da Região Sudeste do Brasil, que oferecem o curso de Biblioteconomia, no mercado de trabalho. De forma mais específica, buscou-se identificar em que grupos do mercado de trabalho, conforme divisão proposta por Valentim (2000), estão inseridos os profissionais que foram foco deste estudo.

Dos 39 cursos de Biblioteconomia em atividade em 2015, no Brasil, 15 estão localizados na Região Sudeste e, destes, nove estão no Estado de São Paulo, enquanto nos Estados do Acre, Rondônia, Roraima, Amapá e Tocantins não há nenhum curso de Biblioteconomia ${ }^{1}$ (CRB 6, 2015)

Uma profissão, uma carreira, um curso, é escolhido pelas aptidões, pela identificação com determinada área. A escolha por um curso como o de Biblioteconomia pressupõe a identificação com a leitura, com a forma mais comum de organização do conhecimento, o livro. Fatores como as oportunidades de emprego na área e afinidade com a pesquisa, apontados por Walter (2008), também são motivos que favorecem a escolha da carreira. A questão de orientação para determinada formação, mais focalizada em um segmento específico, deve ser objeto de atenção e estudo, uma vez que a escolha pela profissão depende do indivíduo e de sua vocação, provavelmente, mas a questão afeita à inserção no

\footnotetext{
${ }^{1}$ Conselho Regional de Biblioteconomia 6ạ região. Cursos de Biblioteconomia no Brasil. Disponível em: < http://www.crb6.org.br/carreira.php>. Acesso em: 5 jun. 2015.
} 
mercado de trabalho pode ser influenciada por outros fatores como, por exemplo, a formação recebida ou as oportunidades que surgem.

Estudos realizados na Universidade de São Paulo, nos anos de 2010 e 2011, no curso de Ciências da Informação e da Documentação do Departamento de Educação, Informação e Comunicação, em Ribeirão Preto, tinham por objetivo verificar se as ênfases que o curso oferece no último ano da graduação, influenciaram a inserção de seus discentes no mercado de trabalho. A suposição era de que, se o curso possui um direcionamento em sua grade curricular esperava-se que tal formação auxiliasse na inserção destes profissionais no mercado de trabalho. Os resultados obtidos na pesquisa foram favoráveis à suposição inicial e demonstraram ainda, que organizações privadas oferecem diversas possibilidades de atuação ao egresso do curso, tendo em vista o mapeamento realizado no mercado de trabalho dos referidos profissionais. (GARCIA et al., 2013)

Tais ênfases do curso de Ribeirão Preto consistem em um conjunto de disciplinas que visam capacitar o aluno para o trabalho com a organização e disseminação da informação em instituições públicas e/ou privadas ligadas à área de saúde (hospitais, consultórios, sistemas de saúde etc.), educação (escolas, bibliotecas, centros culturais) e negócios (empresas, consultorias, administração de negócios etc.), dentre outros ambientes que têm a prestação de serviços de informação como função básica. (UNIVERSIDADE DE SÃO PAULO, [s.d])

Em um cenário de transformações tecnológicas, conflito de imagem profissional, estereótipos ultrapassados e de inúmeras transformações em todos os setores da vida humana, estão presentes as exigências de mercado de trabalho. O progresso tecnológico é evidente, enquanto principal facilitador no processo comunicacional. Em tempos em que é possível processar, armazenar, recuperar e comunicar informação em qualquer formato, sem interferência de fatores como distância, tempo ou volume (SILVA e CUNHA, 2002) o bibliotecário tem seu papel a cumprir.

Em razão dos poucos estudos sobre a relação do perfil profissional com direcionamento de atuação no mercado de trabalho, surgiu o questionamento acerca de quais seriam os fatores que exerceriam maior ou menor influência na inserção do bibliotecário no mercado de trabalho. Esperava-se que os resultados desta pesquisa pudessem contribuir no sentido de verificar se as formações acadêmicas recebidas durante a graduação influenciariam a inserção dos profissionais da informação, em especial os bibliotecários, no mercado de trabalho, ou se são as oportunidades que o mercado de trabalho oferece que delineariam o caminho seguido. 


\section{Mercado de Trabalho do Bibliotecário}

Em 1983, Lancaster apud Costa e Moraes (1992), afirmava que a Biblioteconomia era considerada a mais institucionalizada das profissões, afirmando que a evolução da área estaria direta e dependentemente relacionada a uma instituição, cuja identidade é a biblioteca. Ainda de acordo com o autor, o ensino da Biblioteconomia teve seu início calcado nas bibliotecas, situação que perdurou no tempo, na medida em que a maioria das entidades educacionais e profissionais recebem a denominação de escolas ou associações de bibliotecas e não de bibliotecários.

No mínimo - destaca o autor - há uma razão muito patente para esta situação. As bibliotecas existiram antes dos bibliotecários. Além do mais, por vários séculos, os bibliotecários não eram mais que guarda ou curador de materiais. O bibliotecário como provedor de alguma forma de serviço profissional é comparativamente considerado como um novo fenômeno. (LANCASTER, 1983, p.1, apud COSTA E MORAES 1992, p. 11)

Lancaster (1983, apud COSTA E MORAES 1992, p. 11) observava ainda, que, no passado, alguns profissionais já exerciam suas funções fora do âmbito da biblioteca, citando, como exemplo, "[...] os bibliógrafos de assuntos filiados à biblioteca da universidade alemã que, no início do século XX, trabalhavam diretamente nos departamentos correspondentes à sua própria área de especialidade". Ele prosseguiu apontando que o processo de desinstitucionalização na Biblioteconomia foi mais fortemente relacionado às modificações provocadas pelas inovações tecnológicas (da informática e telecomunicações) e que o futuro da biblioteca seria, na melhor das hipóteses, de ocupar um papel secundário.

Isto é, as pessoas terão muito pouca razão para visitar a biblioteca com a finalidade de obter acesso aos recursos informacionais. Acredito que seja altamente significativo o proprietário de um computador doméstico ou o dono de uma casa que tenham à disposição determinadas formas de televisão interativa manterem a mesma situação, o acesso relacionado às fontes de informação eletrônica, como se as bibliotecas estivessem somente na década passada. (LANCASTER, 1983, p. 1, apud COSTA E MORAES 1992, p. 11)

Ou seja, desde meados da década de 1980 já se discutia sobre uma nova variável, relacionada ao mercado de trabalho do bibliotecário, que seria sua atuação fora das bibliotecas.

Anterior às reformas do currículo mínimo de Biblioteconomia o bibliotecário, em geral, em seu processo de formação, era mais comumente direcionado a atuar no espaço físico das bibliotecas. No entanto, com as mudanças de paradigma e a instituição de novos mercados profissionais as exigências sobre o bibliotecário aumentaram muito no que tange o uso das novas tecnologias para o tratamento, manuseio e disseminação da informação (GUIMARÃES, 1997). 
Estudos realizados por Baptista e Muller (2004) mostraram que as organizações não convencionais, a saber, empresas privadas e até mesmo a sociedade em geral, desconheciam o trabalho do bibliotecário fora das bibliotecas. Assim, o estereótipo tradicional criado em torno destes profissionais contribuía, e de certo modo ainda se mantém essa imagem associada, para as dificuldades de atuação além dos espaços convencionais. O desconhecimento da profissão por parte da sociedade também pode, potencialmente, estreitar o campo de atuação aos ambientes tradicionais.

No início do século XXI Valentim (2000) explicitava que a despeito dessa amplitude de possibilidades de atuação para os bibliotecários, em ambientes distintos e diversificados, como bancos e bases de dados, editoras, internet, entre outros, também era considerado pequeno 0 número dos que atuavam em funções que não estavam diretamente relacionadas ao ambiente das bibliotecas.

\section{Formação Acadêmica e Atuação Profissional do Bibliotecário}

Segundo a Classificação Brasileira de Ocupações (CBO), os Profissionais da Informação, grupo ao qual o Bibliotecário pertence, são aqueles que:

[...] disponibilizam informação em qualquer suporte; gerenciam unidades como bibliotecas, centros de documentação, centros de informação e correlatos, além de redes e sistemas de informação. Tratam tecnicamente e desenvolvem recursos informacionais; disseminam informação com o objetivo de facilitar o acesso e geração do conhecimento; desenvolvem estudos e pesquisas; realizam difusão cultural; desenvolvem ações educativas. Podem prestar serviços de assessoria e consultoria (BRASIL, 2010) $)^{2}$.

Com o avanço das Tecnologias da Informação, que ampliaram a visibilidade e as possibilidades de serviços e de acessos, as escolas de Biblioteconomia estão tendo que se adaptar a essa nova realidade, uma vez que as inovações constantes representam um desafio a ser superado.

O que se percebe na Biblioteconomia é que já no final do século $X X$, o mercado e as circunstâncias passaram a exigir um aperfeiçoamento e aplicação de novas técnicas, pautadas nos serviços informatizados e nos sistemas de informação, que têm sua complexidade amplificada a cada segundo.

A tarefa não é fácil, mas acredito ser uma questão de coerência com essa nova ordem social que se apresenta pois se outrora poder-se-ia falar em "reservas de mercado profissional", hoje expressões dessa natureza foram substituídas por outras mais substanciais (e coerentes!) como competências

\footnotetext{
${ }^{2}$ BRASIL. Ministério do Trabalho. Classificação Brasileira de Ocupações. 3. ed. Brasília: TEM, SPPE. 2010. Disponível em: <http://www.mtecbo.gov.br/cbosite/pages/downloads.jsf>. Acesso em: 13 jun. 2015.
} 
e ética profissional. Ao ensino, pois, duas palavras-de-ordem poderiam ser propostas: integração e pesquisa e, às entidades de classe, por sua vez, qualidade e atualização profissional (GUIMARÃES, 1997, p. 134).

Conforme Brittain (1985, p. 117) “[...] a Biblioteconomia e a Ciência da Informação têm custado a compreender que, de modo crescente, nossos graduados dirigem-se para empregos onde não aparecem as palavras biblioteca ou informação na descrição do cargo. " Apesar do texto de Brittain ter sido escrito há 30 anos, suas colocações podem ser consideradas pertinentes, visto que a atuação ampla do bibliotecário ainda parece pouco conhecida e socialmente mais entendida como atrelada às bibliotecas.

Um conceito associado ao bibliotecário, o moderno profissional da informação, vem sendo discutido desde o final da década de 1990 e é reflexo do contexto sócio-histórico mundial pelo qual a Biblioteconomia e a Ciência da Informação traçaram sua história. 0 conceito de um profissional holístico, aberto, flexível, criativo, dinâmico e pró-ativo é cada vez mais enfatizado e discutido, pois é esse perfil que o mercado de trabalho busca nos profissionais da informação. Neste sentido, estudiosos da área, como Guimarães, Baptista e Mueller, destacam a importância de as instituições formadoras destes profissionais preocuparem-se em adequar os currículos dos cursos para formarem esses modernos profissionais da informação, atentos às especificidades de cada realidade institucional e capazes de atuar em diversas áreas, tendo sempre em mente a importância de fornecer "a informação certa, ao cliente certo".

Tanto os currículos quanto o nome dos cursos passaram por inúmeras modificações, o espaço de trabalho dos profissionais foi ampliado e a conjuntura social ao longo dos anos moldou as necessidades e possibilidades de atuação do bibliotecário. Os espaços profissionais que surgiram vêm sendo ocupados gradativamente, pois cada vez mais não só o mercado como também os profissionais aprimoram seus conhecimentos e, consequentemente, o profissional se qualifica e se torna competente para atender a demanda. É fato que a demanda emergente dessas competências variadas, bem como a questão das grades e currículos são temas que geraram e ainda permeiam muitas discussões, mas é importante enfatizar que a atuação heterogênea e cada vez mais pulverizada do bibliotecário já mostrava vertentes mais otimistas, conforme Mueller em 1989.

A preparação profissional para as áreas que lidam com informação tem uma proposta diferente das outras áreas, justamente pela natureza do objeto informação e seus desdobramentos, que guiam e direcionam a atuação do bibliotecário. Os fatos que afetam a vida em sociedade, as descobertas científicas e tecnológicas, bem como as ocorrências da vida política afetam o modo como as pessoas buscam, usam e sentem necessidade de se informar. 
Do mesmo modo, a atividade profissional dos que se dedicam a buscar respostas para tais necessidades de informação está sujeita às mesmas influências. Sendo assim, a preparação destes profissionais deve proporcionar conhecimento e flexibilidade suficiente para que 0 profissional seja capaz de se adaptar e atender as novas demandas. Ao indivíduo que busca pela informação, na maioria das vezes, não interessa se a informação é fornecida por um bibliotecário ou por um profissional de outra área, o que importa é que o acesso seja eficiente e a informação confiável (MUELLER, 1989).

\begin{abstract}
Ainda que todo aspecto legal seja ignorado a preocupação da definição dos limites de nosso campo de trabalho, acordada por todos, sociedade, classe profissional e escola, é indispensável, pois não é possível preparar recursos humanos e planejar para o futuro sem que sejam definidos os campos de trabalho, áreas de atuação e objetivos da profissão para a qual se prepara (MUELLER, 1989, p. 179).
\end{abstract}

Na tentativa de atender o campo de trabalho da "profissão da informação" faz-se necessário repensar os cursos, as estruturas e delimitar os espaços para que seja possível traçar os perfis e pontuar competências e habilidades. "[...] se de um lado restringimos os campos de interesse, por outro devemos aprofundar o estudo em todos os aspectos deste campo." (MUELLER, 1989, p. 184).

O levantamento acerca do tema formação profissional em relação ao mercado de trabalho mostrou-se escasso, embora se constitua um ponto importante para o desenvolvimento e avanço das pesquisas na área. Sendo assim, os estudos realizados por Valentim (2000), podem ser considerados os mais recentes quanto à delimitação de mercado de trabalho do bibliotecário. Segundo a autora, é possível distribuir o mercado de trabalho do bibliotecário em três grupos:

a) "Mercado informacional tradicional" - em que predominam as organizações que recebem a denominação de grandes empregadoras dos profissionais da informação; estão presentes nos diversos setores da economia e se concentram majoritariamente no ramo da administração pública, que no geral assiste à população no acesso à cultura, lazer e recreação. Esta tipologia de mercado é bem conhecida e compreende: bibliotecas em geral (bibliotecas públicas, bibliotecas escolares, bibliotecas infantojuvenis, bibliotecas especializadas, bibliotecas universitárias), centros de cultura, arquivos e museus.

b) "Mercado informacional existente e pouco ocupado" - em que predominam instituições cuja atividade principal é voltada para organização e recuperação da informação. O que se pode observar desta fatia do mercado é que poucas organizações que buscam este tipo de serviço contratam profissionais da informação, em função do 
desconhecimento da profissão, dos benefícios do serviço e dos custos, considerados na maioria das vezes, supérfluos. Neste ramo mercadológico estão as editoras, livrarias, jornais, locadoras (de vídeo, DVD e livros) e empresas privadas.

c) "Mercado informacional de tendências" - considerado um mercado de fronteiras em que profissionais de diferentes nichos podem competir. Destaca-se neste grupo a vantagem dos que trabalham com tecnologia da informação, pois o foco do mercado esta direcionado para estes profissionais inseridos na era digital e tecnológica. Portanto a abrangência de mercado se limita a esta área, com atuação em: base de dados, intranet, internet e serviços de consultoria ou assessoria.

Quanto “[...] mais coeso e lógico for o corpo de conhecimento que dá sustentação a um grupo profissional, maior a resistência dessa profissão aos ataques de rivais. " (MUELLER, 2004, p.35). Por outro lado, se a preocupação dos profissionais não estiver voltada também para seu espaço tradicional a profissão tende a perder a identidade e ser substituída pelo imperativo da tecnologia (PENA, 2007).

Análises de mercado internacionais como o trabalho de Cronin, Stiffer e Day (1993), apontaram para a difusão e amplitude do mercado, bem como a valorização da experiência profissional e dos títulos acadêmicos. Já nesta época se falava em investigação sobre a atuação dos egressos no mercado de trabalho para verificar se estavam obtendo êxito. Estudos conduzidos no Brasil, como o trabalho de Polke, Araújo e Cesarino (1976) mapearam a evolução do curso da Universidade Federal de Minas Gerais, traçando o perfil do bibliotecário nos anos 1970: jovens, a maioria do sexo feminino, com salário classificado como regular e contentes com a escolha da profissão.

A Federação Internacional de Informação e Documentação (FID) criou, em 1991, o Grupo de Interesse específico sobre Papéis, Carreiras e Desenvolvimento do Moderno Profissional da Informação (SIG FID/MIP). Este grupo realizou pesquisas no mundo todo para investigar as mudanças no mundo do trabalho dos bibliotecários, bem como a influência sobre o perfil dos profissionais da informação em constante mudança (PENA, 2007, p. 74).

A maioria dos profissionais da amostra escolhida era formada por mulheres, geralmente casadas. A grande maioria atuava na cidade de Vitória e formouse na Universidade Federal do Espírito Santo (91,8\%), com uma participação de egressos da UFMG em $4,7 \%$ das entrevistas. As demais instituições somavam $3,6 \%$ da população pesquisada. Uma das constatações é que 53,26\% dos entrevistados atuavam em instituições públicas; $46,65 \%$ em instituição privada e, apenas 1,09\% em instituição de economia mista. Tendo em vista que mais da metade é funcionário público, o concurso público foi a principal forma de acesso ao atual emprego (31,52\%), seguida de 26,09\% por indicação e os $11,96 \%$ restantes através de processo seletivo com o empregador. Em relação ao setor em que os profissionais atuavam, o estudo evidenciou que $69,5 \%$ dos entrevistados estavam empregados em 
bibliotecas, outros $8,7 \%$ em centros de documentação e $7 \%$ em arquivos. Portanto, percebe-se que mais de $80 \%$ dos profissionais da informação no Espírito Santo exerciam atividades profissionais no setor tradicional do mercado de trabalho (PENA, 2007, p. 75).

O setor público emprega boa parte dos bibliotecários, pois segundo outra pesquisa de mercado de trabalho realizada por Souza e Nastri em 1996, o setor público já empregava mais da metade dos bibliotecários registrados no Conselho Regional de Biblioteconomia (CRB8).

Em relação à atuação dos bibliotecários no ramo da prestação de serviços autônomos, de assessoria a pessoas físicas e empresas para organização de seus estoques de informação, os números encontrados pelas pesquisas de Baptista (2000) foram baixos. Aproximadamente 15\% do número total de profissionais da informação existentes na época. No Brasil não é comum a ocorrência de bibliotecários autônomos e isso pode ser comprovado por dados do próprio CRB8, que aponta para a não obrigatoriedade do registro de firmas prestadoras de serviço neste ramo mercadológico (BAPTISTA, 2000).

Após mais de 10 anos do estudo realizado por Baptista, a literatura construída acerca do tema, não aborda aspectos que apontam mudança no cenário anterior:

\footnotetext{
Como visto, a pesquisa revelou inúmeras lacunas nos serviços prestados por empresas de consultoria informacional no Brasil. Contudo, dado as limitações da pesquisa, não é possível identificar as causas da existência dessas lacunas. $O$ que de fato pode-se perceber é que o bibliotecário passa por uma transição e precisa tornar-se mais que um eficiente gerenciador de serviços técnicos de bibliotecas. Mediante os serviços apontados e o que discorre a $\mathrm{CBO}$, o bibliotecário passa a ter um papel mais efetivo na gestão da informação no âmbito de consultoria informacional. Nesse sentido, um maior e melhor conhecimento sobre como e onde esse profissional pode atuar, bem como um estudo de necessidades mercadológicas no que concerne à gestão da informação, podem contribuir para o estabelecimento de um negócio com o objetivo de suprir as lacunas do rol de serviços identificadas por esta pesquisa. (MILANO; DAVOK, 2009, p. 271)
}

A partir de 2003 pode ser observada uma expansão de vagas para os bibliotecários, em função do aumento significativo da instalação de instituições de ensino superior em todas as áreas e como política nacional de aumento de pessoas com formação superior. Como as faculdades e universidades precisavam também, obrigatoriamente, de bibliotecas para dar suporte ao ensino, pesquisa e extensão, consequentemente foi ampliada a contratação de bibliotecários para administrar e coordenar esses espaços. É importante ressaltar que neste mesmo período o MEC modificou as regras de avaliação das instituições e um dos novos critérios estava relacionado à avaliação das bibliotecas em geral (PENA, 2007). 


\section{Procedimentos Metodológicos}

Este estudo foi de caráter descritivo, "[...] quando se deseja descrever as características de um fenômeno [...] " (RICHARDSON et al., 2008, p. 66), uma vez que a intenção é verificar determinadas características e comportamentos na população escolhida. Também se pode caracterizar esta pesquisa como sendo exploratória, método utilizado para identificar tendências, interesses e comportamentos, além de formular hipóteses e expor opiniões a respeito dos temas, após estudos práticos ou teóricos. (GIL, 1999).

Do ponto de vista da forma e abordagem do problema, esta pesquisa caracteriza-se como mista, uma vez que se fez uso dos métodos qualitativos (quando considera que existe uma relação entre o mundo e o sujeito que não pode ser traduzida em números; a pesquisa é descritiva e o pesquisador tende a analisar seus dados indutivamente.), e quantitativos (exposição de ordem exclusivamente numérica de um dado fenômeno). (LAKATOS; MARCONI, 2010).

A amostra utilizada para o desenvolvimento da pesquisa foi composta pelos egressos formados no período entre 2010 e 2014 da: USP (Universidade de São Paulo), UNESP (Universidade Estadual Paulista "Júlio de Mesquita Filho"), UFMG (Universidade Federal de Minas Gerais), UFSCAR (Universidade Federal de São Carlos), UNIRIO (Universidade Federal do Estado do Rio de Janeiro) e UFES (Universidade Federal do Espírito Santo). ${ }^{3}$

Ao todo foram seis universidades e sete cursos, pois a USP oferece dois cursos, sendo um na cidade de São Paulo e outro em Ribeirão Preto. A escolha da região se deveu tanto à maior concentração de cursos de Biblioteconomia e/ou Ciência da Informação oferecidos por instituições públicas, quanto por terem as melhores notas nos Programas de Pós-Graduação na avaliação da Coordenação de Aperfeiçoamento de Pessoal de Nível Superior (CAPES) em relação aos das demais regiões.

O acesso aos dados referentes aos egressos das Universidades foco deste estudo ocorreu de duas formas:

1) inicialmente o contato foi realizado com todas as Universidades via email e telefone.

Posteriormente, um ofício com a solicitação dos emails dos egressos foi encaminhado

\footnotetext{
${ }^{3}$ A UFES (Universidade Federal do Espírito Santos), a UFF (Universidade Federal Fluminense) e a UFRJ (Universidade Federal do Rio de Janeiro) também fariam parte do escopo de pesquisa, porém tanto os emails enviados durante os anos de 2014 e 2015, quanto as ligações, no sentido de obter os números de egressos formados na universidade no período delimitado para a pesquisa, bem como as solicitações para disponibilizar o link do questionário por emails aos egressos, ou no site da instituição, não foram respondidos. Desse modo, diante da inexistência de dados, a UFES, a UFF e a UFRJ foram descartadas do universo de pesquisa.
} 
descrevendo os objetivos da pesquisa, bem como constando as informações sobre sigilo dos endereços eletrônicos;

2) os CRB das regiões 6 (Minas Gerais) 7 (Espírito Santo e Rio de Janeiro) e 8 (São Paulo) também foram contatados a fim de disponibilizar os dados referentes aos bibliotecários inscritos por ano.

Tendo em vista as dificuldades encontradas tanto junto às Universidades, em fornecer os contatos dos egressos, quanto junto aos CRB, em fornecer o quantitativo de profissionais inscritos e os contatos para envio dos questionários, optou-se por enviar aos Conselhos e às Universidades o link do questionário a fim de que disponibilizassem nos respectivos portais e/ou enviassem o link para os egressos por email. O procedimento foi adotado por todas as instituições e CRB. No total foram enviados 388 emails e recebidas 179 respostas.

Pesquisas que envolvem os bibliotecários necessariamente requerem o apoio dos Conselhos Regionais de Biblioteconomia, que são detentores dos cadastros mais confiáveis de endereços no Brasil. Ainda que se tenha consciência de que dados pessoais são sensíveis e requerem cuidados por quem detém as informações, seria interessante que as Escolas de Biblioteconomia e o Conselho Federal de Biblioteconomia repensassem estratégias de acesso que permitissem o contato, em pesquisas que envolvam os profissionais, de forma a não inviabilizar estudos que possam contribuir para o conhecimento e estudo da própria profissão e dos que nela estão inseridos.

Como instrumento de coleta, esta pesquisa foi realizada por questionário composto de 21 perguntas fechadas e quatro perguntas abertas, o que possibilitou a utilização de método misto, quantitativo e qualitativo, para análise e tratamento dos dados. Para elaboração das perguntas, buscou-se na literatura e nos conceitos essenciais dos autores, as premissas e afirmações para montagem das questões com afirmações acerca de cada um dos temas.

Para classificação e medição das afirmativas, utilizou-se a escala de Likert (concordância ou discordância), para aquelas afirmativas que comportavam, e avaliação qualitativa naquelas em que se requeria a opinião valorativa do respondente (Péssimo a Ótimo). A escala Likert é uma escala psicométrica das mais conhecidas e utilizadas em pesquisa quantitativa, já que pretende registrar o nível de concordância ou discordância com uma declaração dada ou a avaliação de uma afirmação. Ela mede atitudes e comportamentos utilizando opções de resposta que variam de um extremo a outro (por exemplo, de concordo totalmente para discordo totalmente). Ao contrário de uma simples pergunta de resposta "sim ou não", uma Escala Likert permite descobrir níveis de opinião.

Isso pode ser particularmente útil para temas e assuntos sensíveis ou desafiadores. Ter um conjunto de respostas também irá ajudá-lo a identificar 
mais facilmente as áreas a melhorar - se estiver coletando a opinião dos respondentes sobre a qualidade de algum serviço. (LIKERT, 1932, p. 46)

Foram realizadas ainda, entrevistas com um bibliotecário formado em cada uma das universidades que compreenderam o escopo de pesquisa. Faz-se necessário destacar que esta amostra de conveniência foi estabelecida a fim de detectar impressões, opiniões e estabelecer discussões acerca do objeto de estudo, que por meio da utilização de questionários não são possíveis.

Para o tratamento dos dados qualitativos, provenientes de questões abertas e das entrevistas realizadas, foi utilizada a técnica de análise de conteúdo tanto para análise das questões abertas dos questionários quanto para a parte conceitual e teórica, de onde foram retirados os conceitos e abordagens estabelecidos a priori.

Conforme propõem Richardson et al. (2008), a análise de conteúdo possui três fases principais:

- estabelecer a unidade de análise - que se refere ao elemento básico de análise, relativo às palavras chave e/ou às proposições sobre determinado assunto.

- Determinar as categorias de análises - que se refere à seleção e classificação dos dados. A chamada categoria de matéria que trata da identificação dos assuntos abordados na comunicação.

- Selecionar uma amostra do material de análise - que trata dos critérios adotados para a seleção da amostra.

\section{Perfil Pessoal e Profissional da Amostra}

Um extrato dos resultados é apresentado a seguir, com a caracterização do perfil da população estudada, seguida dos dados acerca dos segmentos de atuação:

$\checkmark$ Sexo: 103 mulheres e 76 homens. "As pesquisas na área da biblioteconomia sempre demonstraram que esta é uma profissão feminina, adequada à nossa natureza", considerando a predominância do sexo feminino na área. Enquanto mulheres, de acordo com nossa formação, seríamos levadas a prestar serviços ou cuidados, "[...] magistério, enfermagem, nutrição, biblioteconomia, que de alguma forma são extensões das atividades domésticas, senão vejamos: a enfermeira cuida dos doentes, a nutricionista da comida, a professora das crianças e a bibliotecária da arrumação da casa dos livros. " (FERREIRA, 2003, p. 191). Apesar da predominância feminina, percebe-se alteração no quadro, visto que pesquisas anteriores apontam para uma minoria de bibliotecários homens. Ainda é clara a predominância de mulheres exercendo a profissão, no entanto pesquisas de gênero na área apontam para 
predominância do sexo masculino em cargos de gestão na Biblioteconomia. (FERREIRA; BORGES; BORGES, 2010)

Idade: entre 24 e 38 anos. Considerando que o grupo da pesquisa foi formado por egressos entre os anos de 2010 e 2014, a faixa etária dos respondentes nos permite ponderar que provavelmente a maioria entrou na universidade no período que se considera usual (entre 18 e 20 anos), uma vez que não foram recebidos questionários de bibliotecários com mais de 38 anos. Outro ponto a se considerar é que o grupo respondente optou pelo curso de Biblioteconomia como carreira e não como uma segunda graduação, como se observou na pesquisa de Ferreira e Borges (2010).

$\checkmark$ Curso: todos formados em uma das universidades públicas da Região Sudeste do Brasil, com formação em Biblioteconomia (Gráfico 1). Nenhum dos seus respondentes, registrados nos CRB que cobrem a região sudeste, se formou em outra região. Como a divulgação do questionário foi seguida de um resumo sobre a amostra de interesse da pesquisa, acredita-se que tal informação auxiliou no sentido de que os bibliotecários formados em outras regiões, antes de responder, observavam no resumo que não faziam parte do escopo de estudo e assim, não respondiam a pesquisa, ou que existe pouca mobilidade entre os profissionais, que permanecem nas regiões em que se formam. Como essa questão não foi pesquisada, não é possível fazer nenhuma afirmação.

$\checkmark$ Do total de respondentes, 16 deles não trabalham.

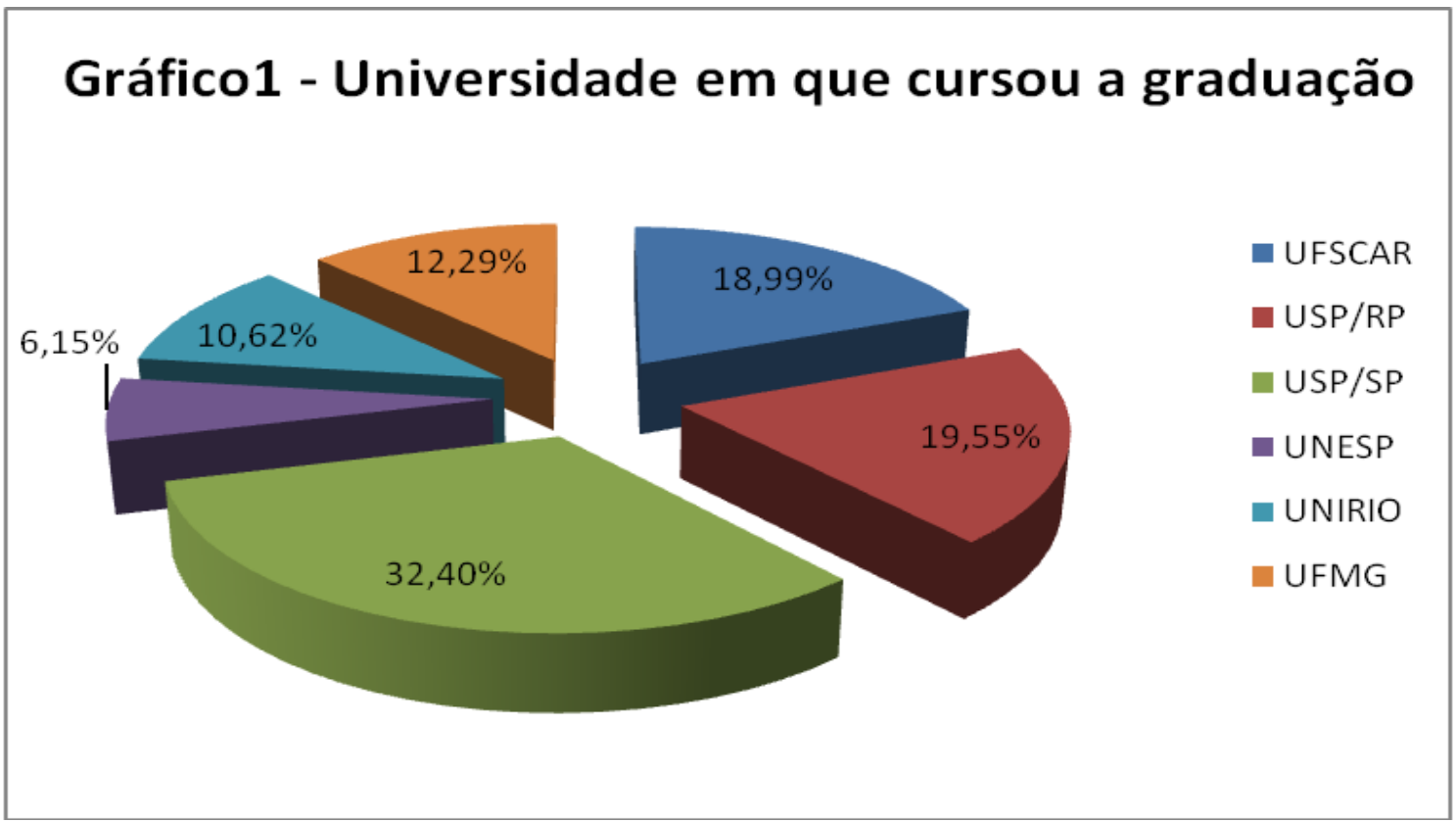

Fonte: as autoras. 


\section{Gráfico 2 - Formação complementar}

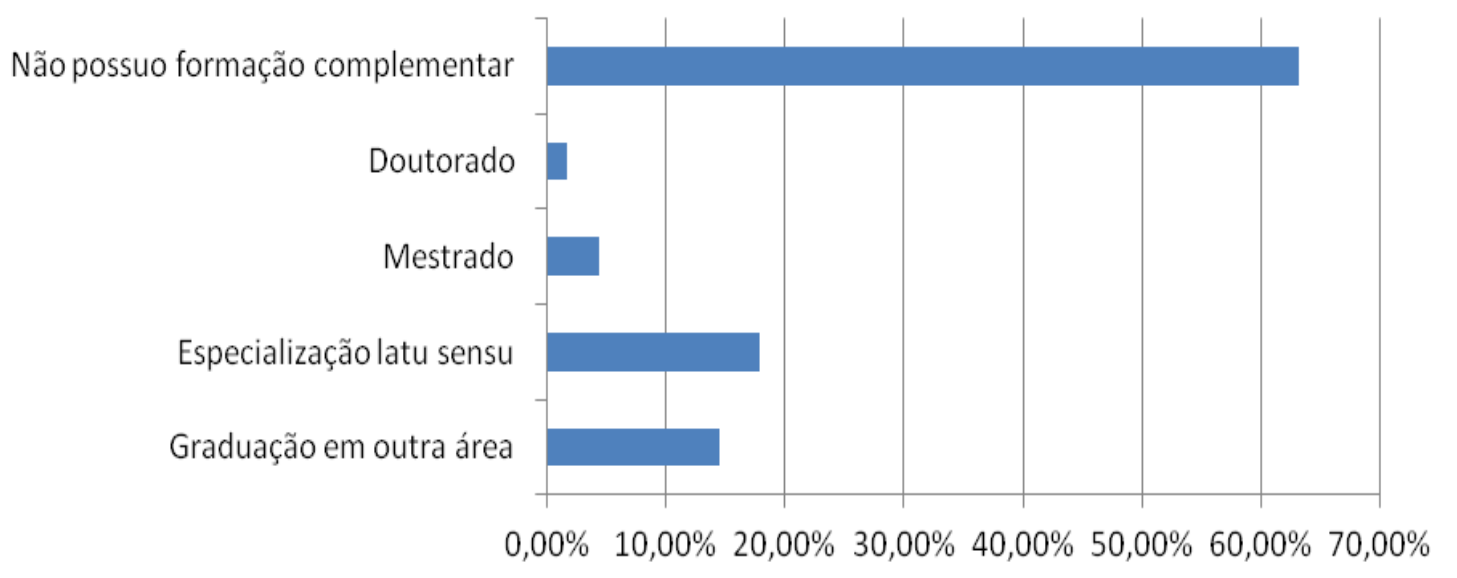

Fonte: as autoras.

Quanto à formação complementar, percebe-se, de acordo com o gráfico 2, que 67,60\% dos bibliotecários não possuem nenhum tipo de formação complementar e que 14,52\% possuem graduação em outra área. Os cursos mencionados, em ordem de maior incidência dentre os respondentes, foram: Direito, Administração, Sistemas de Informação, Pedagogia e Letras. A maioria justificou a segunda graduação como "necessidade de conhecimento em outra área" devido à função e/ou trabalho que exercem, outros, entretanto por "satisfação e/ou realização pessoal". A maioria dos bibliotecários, 91,07\%, à época da pesquisa (a coleta de dados foi feita entre março e abril de 2015) estava trabalhando. Somente 8,93\% indicaram que não estavam trabalhando e, desses, 6,05\% informaram que estão cursando Pós-Graduação stricto sensu e apenas 2,88\% não estão trabalhando e/ou estudando.

Percebe-se que a porcentagem de bibliotecários empregados é alta quando comparada com o índice de 7,9\% de desemprego registrado nos três primeiros meses de 2015 no país ${ }^{4}$. Estes dados confirmam pesquisas e matérias veiculadas na internet ${ }^{5}$ que indicam a Biblioteconomia como carreira ainda promissora.

De uma equipe de 14 técnicos especialistas da empresa Knowtec, em Florianópolis, nove são bibliotecários, entre eles Camila Meneghetti. A empresa trabalha com a coleta estratégica de informações, pesquisa e análise de mercado para promover inteligência competitiva e inovação, 0 grupo oferece consultoria a diferentes setores, do ramo calçadista ao

4 PASSARINHO, Sandra. Taxa de desemprego no Brasil foi a mais alta em dois anos, diz IBGE. Jornal da Globo. Disponível em: <http://g1.globo.com/jornal-da-globo/noticia/2015/05/taxa-de-desemprego-no-brasil-foi-mais-altaem-dois-anos-diz-ibge.html>. Acesso em: 14 jun. 2015.

5 MATHIAS, Letícia. Biblioteconomia: um curso promissor que tem perfil jovem e profissionais gestores da informação. Notícias do dia. Disponível em: <http://ndonline.com.br/florianopolis/noticias/65243-biblioteconomiaum-curso-promissor-que-tem-perfil-jovem-e-profissionais-gestores-da-informacao.html>. Acesso em: 14 jun. 2015. 
agronegócio. A função dos bibliotecários neste processo é realizar pesquisas constantes e entregar informações que influenciem e até determinem decisões "Nosso trabalho consiste em saber antes, levar a informação antecipada ao cliente", conta Camila. (MATHIAS, 2013, p. 1)

Observa-se que no universo de bibliotecários que estão trabalhando, de alguma forma todos estão inseridos em atividades que têm relação com informação, o que também pode indicar que a Biblioteconomia ainda pode ser uma área atraente, além de, aparentemente, alguns campos estarem começando a ser ocupados pelos profissionais. Dos 19,40\% que não trabalham em bibliotecas, 12,40\% ocupam o que Valentim (2000) chamou de "mercado existente e pouco ocupado", tendo sido assinalados, nos questionários, principalmente editoras e empresas privadas; e 4,22\% dos bibliotecários ocupa o "mercado informacional de tendências" uma vez que exercem funções na área de tecnologia da informação, consultoria e assessoria.

No que se refere ao âmbito da formação profissional e mercado de trabalho, nota-se que os bibliotecários participantes desta pesquisa, em sua maioria:

$\checkmark$ Concordam que a grade curricular de seus cursos foi suficiente para a inserção no mercado de trabalho $(73,6 \%)$;

$\checkmark$ Que as disciplinas dos cursos de Biblioteconomia são muito teóricas (84,5\%);

$\checkmark$ Que a grade curricular esta defasada em relação às exigências do mercado de trabalho $(89,3 \%)$;

Que um diferencial na carreira dos bibliotecários são as competências profissionais $(63,1 \%)$;

Que os cursos de biblioteconomia habilitam os estudantes para ingresso no mercado de trabalho $(79,5 \%)$.

Apesar de se utilizar de uma escala de cinco possíveis respostas, verifica-se a concentração maior de respostas em posicionamentos claros, como "concordo totalmente" ou "discordo totalmente".

Chama atenção o fato de que a maioria dos respondentes acha que seu curso foi teórico, que o currículo está defasado, no entanto, a maioria dos seus respondentes está empregada mesmo tendo se formado há relativamente pouco tempo. Apesar de haver críticas aos cursos, aparentemente isso não foi barreira para a empregabilidade desses bibliotecários. É possível questionar se, com o ingresso no mercado de trabalho as pessoas percebem que poderiam ser mais bem preparadas? Em que sentido? Embora esta pesquisa não tenha investigado este aspecto, os resultados podem ser futuramente pesquisados, para tentar identificar as lacunas que os profissionais percebem em sua formação, quando no exercício profissional efetivo. 
Os participantes da pesquisa foram questionados acerca do objetivo geral da pesquisa: "Você acredita que a formação profissional é um fator de influência para a inserção do bibliotecário no mercado de trabalho? De que forma? ", e observa-se que 6,2\% dos respondentes afirmaram que as disciplinas específicas cursadas na graduação direcionam a área de atuação profissional; 4,6\% disseram que o conhecimento específico da área de atuação é indispensável para o exercício da profissão e 11,1\% afirmaram que a formação profissional é um fator determinante que vai além da graduação. Somados, estes dados, $21,9 \%$ das respostas obtidas apontaram a formação acadêmica como fator determinante para inserção no mercado de trabalho, ou seja, tais afirmações respondem diretamente ao problema de pesquisa proposto inicialmente.

É possível analisar ainda que 3,10\% dos bibliotecários acreditam que a formação teórica é de extrema importância, em contraposição aos $84,47 \%$ que julgam os cursos demasiado teóricos. Esses 3,10\% são apenas parte dos bibliotecários que discordaram da afirmação de que os cursos são teóricos, visto que um total de $12,10 \%$ não concordou. Teoricamente, o desempenho de atividades relacionadas à informação é melhor, se as pessoas forem preparadas. Nesse sentido, pode-se pensar em ampliar a formação teórica associada ao tratamento, disseminação, organização e armazenamento da informação no contexto tecnológico em constante evolução com propostas novas e arrojadas de uso da informação pelas pessoas em geral.

A maioria dos bibliotecários, 96,80\% acredita que a formação acadêmica é um fator de influência para inserção no mercado de trabalho. As diferenciações se deram nas justificativas para tal julgamento, tendo alguns considerado necessários e indispensáveis os conhecimentos teóricos apreendidos na graduação. $28,10 \%$ indicaram que consideram a formação profissional importante para a inserção no mercado, mas não justificaram sua resposta.

Dos que acreditam que a formação acadêmica não pode ser considerada um fator de influência, $1,10 \%$ justificou a resposta dizendo que o reconhecimento da profissão tem maior influência e que a desvalorização da área contribui mais que a formação acadêmica, seguidos de $2,10 \%$ que apenas assinalaram não acreditar na formação acadêmica como fator de influência, sem justificar a resposta.

Quando questionados sobre os fatores que consideram determinantes para sua inserção no mercado de trabalho, a maioria dos bibliotecários respondeu que:

$\checkmark$ Concorda em linhas gerais que a formação acadêmica facilitou sua inserção no mercado de trabalho, sendo ela o principal fator. Ao somar os respondentes que concordam parcialmente e totalmente com esta afirmação o percentual é de $91,30 \%$. Ainda que com 
críticas, a formação acadêmica parece ser o fator que mais importa no processo de colocação no mercado de trabalho, na visão do grupo participante da pesquisa.

$\checkmark$ Sobre se as qualificações que possuíam quando se formaram, contribuíram para que encontrassem muitas oportunidades de ingresso no mercado de trabalho, os dados dos que discordam parcialmente e concordam parcialmente para esse quesito são quase iguais, assim como a concordância e discordância total, o que apresenta posicionamentos bem distribuídos quanto a esta afirmação, não sendo possível qualquer conclusão.

$\checkmark$ Concorda que quando estavam procurando emprego, a formação ajudou no processo seletivo;

$\checkmark$ E quanto à facilidade de inserção no mercado de trabalho, houve maior discrepância nas respostas, pois a maioria concorda parcialmente, seguido dos que concordam plenamente e dos que discordam parcialmente, desta premissa.

Quadro 1 - Ocupação dos bibliotecários no mercado de trabalho

\begin{tabular}{|c|c|c|c|c|}
\hline $\begin{array}{c}\text { Total de } \\
\text { bibliotecários }\end{array}$ & $\begin{array}{c}\text { Mercado } \\
\text { Informacional } \\
\text { Tradicional }\end{array}$ & $\begin{array}{c}\text { Mercado } \\
\text { Informacional } \\
\text { Existente e Pouco } \\
\text { ocupado }\end{array}$ & $\begin{array}{c}\text { Mercado } \\
\text { Informacional } \\
\text { de Tendências }\end{array}$ & $\begin{array}{c}\text { Não } \\
\text { Trabalha } \\
\text { na Área }\end{array}$ \\
\hline $100 \%=179$ & $74,45 \%=133$ & $12,40 \%=22$ & $4,22 \%=8$ & $\begin{array}{c}6,05 \%= \\
11\end{array}$ \\
\hline
\end{tabular}

Fonte: as autoras.

A partir da delimitação de mercado de trabalho proposta por Valentim (2000), os bibliotecários respondentes desta pesquisa foram alocados em seus ramos conforme o Quadro 1. Faz-se necessário lembrar que $2,88 \%$ dos respondentes não trabalham ou estudam, por isso não foram incluídos em nenhum dos itens desta classificação.

Após a análise da atuação profissional dos egressos dos cursos analisados, percebeu-se que conforme o Quadro 1, a maioria, $74,45 \%$ dos bibliotecários, trabalha no "mercado informacional tradicional", em que predominam as organizações que são as grandes empregadoras dos bibliotecários, que são as bibliotecas em geral, conforme gráfico 3, que mostra a distribuição por tipo. 


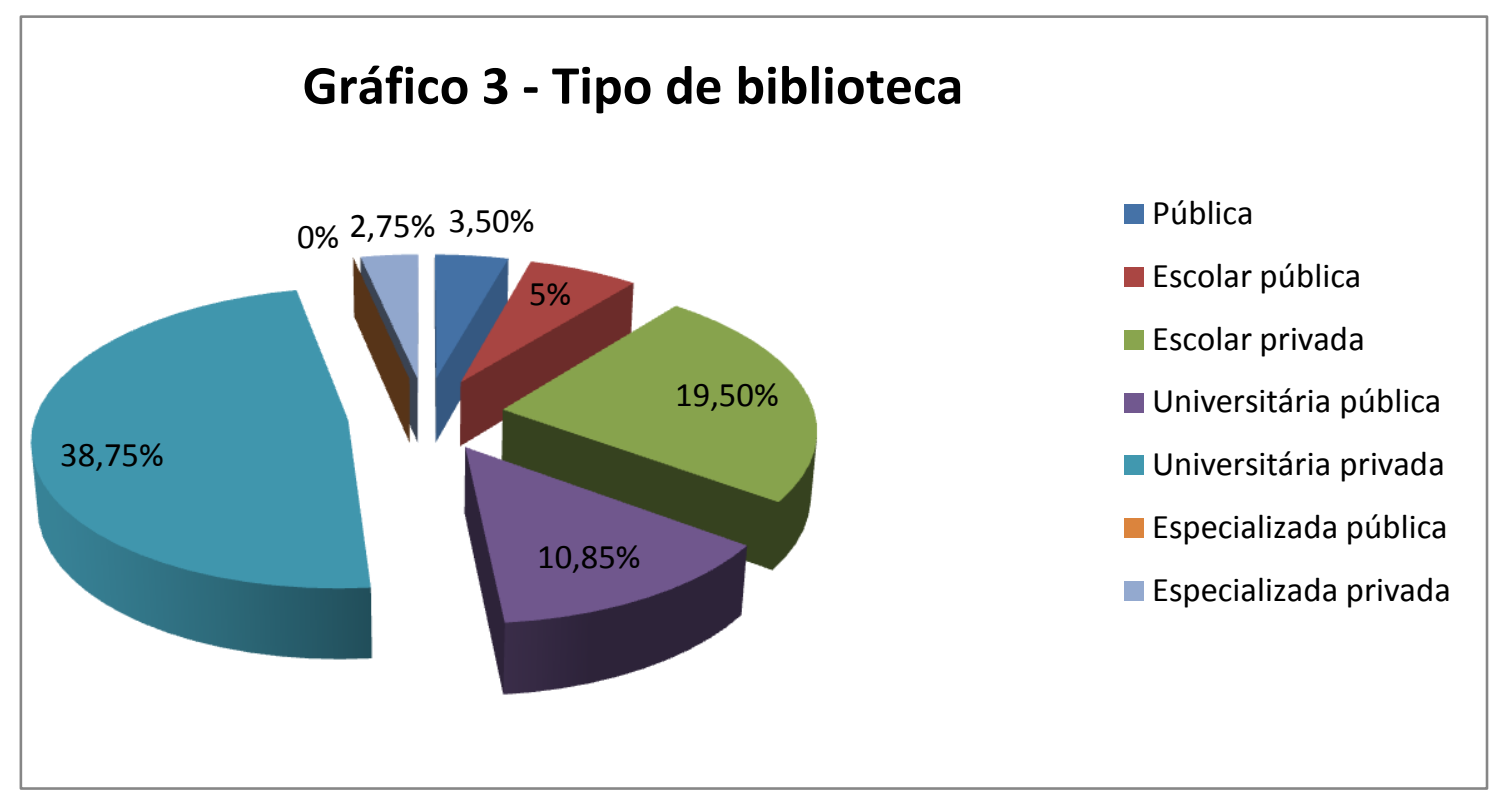

Fonte: as autoras.

O segundo segmento que mais absorve os bibliotecários, $12,40 \%$, nesta pesquisa, foi o "mercado informacional existente e pouco ocupado" em que predominam instituições cuja atividade principal é voltada para organização e recuperação da informação, que inclui editoras, livrarias, jornais, dentre outros. Apenas 4,22\% atuam no "mercado informacional de tendências" que inclui os profissionais que trabalham com tecnologia da informação, bases de dados, consultoria e assessoria.

\section{Conclusões}

Percebeu-se, após análise dos resultados obtidos, que não existe um único fator de influência e sim um conjunto de fatores, que estão associados diretamente ao tipo de ramo e/ou mercado de trabalho escolhido pelo bibliotecário.

Os fatores de influência identificados na literatura e trazidos de forma a compor os instrumentos de coleta de dados; foram os assinalados e julgados pelos respondentes e nenhum outro fator que não foi citado na pesquisa foi descrito e/ou acrescentado. Quanto à importância e /ou relevância, ao pensar o quanto influenciam a inserção dos bibliotecários no mercado de trabalho, os fatores mencionados como mais importantes foram: Formação Acadêmica, Competências Profissionais e Capacidade de Comunicação. Seguidos de: Perfil Profissional, Capacidade de Interação com o Usuário, Boa Apresentação Física, Conhecimento de Informática, Conhecimento de Idiomas e Qualquer Oportunidade que o Mercado Oferece.

Ao propor alocação dos bibliotecários respondentes nos grupos de mercado de trabalho propostos por Valentim (2000), verificou-se, conforme o Quadro 1, que a maioria dos 
bibliotecários trabalha no mercado informacional tradicional, seguidos dos que trabalham no mercado informacional existente e pouco ocupado e em sua minoria, os que ocupam o mercado informacional de tendências. Os estudos de Valentim (2000), embora desenvolvidos a mais de 10 anos, delimitaram o mercado de trabalho da época. Porém aplicando a mesma delimitação, 15 anos depois, percebe-se que a classificação continua adequada, visto que:

$\checkmark$ A maioria dos bibliotecários $(74,45 \%)$ ainda exerce funções dentro das tradicionais bibliotecas;

$\checkmark$ Poucos profissionais (12,40\%) trabalham no ramo de informação em que predominam instituições cuja atividade principal é voltada para organização e recuperação da informação (livrarias, jornais, editoras, empresas privadas);

$\checkmark$ A minoria dos profissionais (4,22\%), se insere no ramo da tecnologia da informação e/ou presta serviços de consultoria e acessória, ocupando assim, o mercado informacional de tendências.

Percebe-se ainda, que os resultados apontam para a formação acadêmica como um dos principais fatores de influência, mas que sozinha não determina a inserção. Os indicadores obtidos através da pesquisa apontaram para uma composição dos fatores relacionados, como formação acadêmica e capacidade de comunicação, por exemplo, mas nenhum isoladamente se destacou, apesar de terem sido atribuídos graus de importância a cada um.

Resta destacar, ainda, que este estudo pontual acerca dos fatores de influência é apenas uma das vertentes, um dos olhares possíveis sobre este universo de pesquisa, destacando como sugestões para estudos futuros: a associação das grades curriculares na composição da formação acadêmica enquanto possíveis fatores de influência; a verificação de se com o ingresso no mercado de trabalho as pessoas percebem que poderiam ser mais bem preparadas e em que sentido isso ocorre; analisar, ainda, o que os editais de concursos públicos pedem para a função de bibliotecários, a fim de verificar que perfis estão sendo requeridos. A carência de estudo na temática de fatores de influência também pode ser considerada uma justificativa para relevância deste tipo de estudo.

\section{Referências}

BAPTISTA, S. G. Profissional da informação, autônomo ou empresário, novas perspectivas de mercado de trabalho. Perspectiva em Ciência da Informação, Belo Horizonte, v. 5, n. 1, p. 9198, jan./jun. 2000.

BAPTISTA, S. G.; MUELLER, S. P. M. (Org.) Profissional da informação: o espaço de trabalho. Brasília: Thesaurus / CID-UnB, 2004. 
BRASIL. MINISTÉRIO DO TRABALHO. Classificação Brasileira de Ocupações. 3. ed. Brasília: TEM, SPPE. 2010. Disponível em: <http://www.mtecbo.gov.br/cbosite/pages/downloads.jsf>. Acesso em: 13 jun. 2015.

BRITTAIN, J. M. Desenvolvimento de currículos nas escolas de Biblioteconomia para enfrentar o desafio da tecnologia da informação. Ciência da Informação, v. 14, n. 2, p. 109-25, 1985. Disponível em:

em: <http://www.google.com.br/search?rlz=1T4SKPB_ptBRBR324BR326\&hl=ptBR\&source=hp\&q= Desenvolvimento+de+curr\%C3\%ADculos+nas+escolas+de+Biblioteconomia\&meta $=\& a q=f \& o q=$ > Acesso em: 11 set. 2014.

CONSELHO REGIONAL DE BIBLIOTECONOMIA 6a REGIÃO. Cursos de Biblioteconomia no Brasil. Disponível em: < http://www.crb6.org.br/carreira.php>. Acesso em: 5 jun. 2015.

COSTA, Antônio Roberto; MORAES, Jurnelei Dias. Desinstitucionalização da informação. Informação e Sociedade. João Pessoa, v. 2, n. 1, p 9-24, 1992. Disponível em: $<$ http://webcache.googleusercontent.com/search?q=cache:6G-fs1iuTcJ:www.brapci.ufpr.br/download.php\%3Fdd0\%3D13961+\&cd=2\&hl=pt-BR\&ct=clnk\&gl=br>. Acesso em: 13 jul. 2015.

CRONIN, B.; STIFFLER, M.; DAY, D. The emergent market for information professionals: educational, opportunities and implications. Library Trends, Chicago, v. 42, n. 2, p. 257-276, 1993.

FERREIRA, M.; BORGES, E. P.; BORGES, L. C. Mercado de trabalho e a desigualdade de gênero na profissão da(o) bibliotecária(o). In: ENCONTRO NACIONAL DE ESTUDANTES DE BIBLIOTECONOMIA, DOCUMENTAÇÃO, GESTÃO E CIÊNCIA DA INFORMAÇÃO, 33., 2010. Biblionline, João Pessoa, n. esp., p. 159-167, 2010. Disponível em: <http://periodicos.ufpb.br/ojs/index.php/biblio/article/viewFile/9637/5227>. Acesso em: 14 jun. 2015.

FERREIRA, M. M. O profissional da informação no mundo do trabalho e as relações de gênero. Transinformação, Campinas, v. 15, n. 2, p. 189-201, maio /ago. 2003.

GIL, Antonio Carlos. Métodos e técnicas de pesquisa social. São Paulo: Atlas, 1999.

GARCIA, L. G. et al. Atuação de profissionais da informação em organizações privadas: o caso CID/USP. In: CASTRO FILHO, Cláudio Marcondes de (Org.). Olhares sobre a atuação do profissional da Ciência da Informação. São Paulo: Todas as Musas, 2013. p. 141-161.

GUIMARÃES, J. A. C. Moderno profissional da informação: elementos para sua formação no Brasil. Transinformação. Campinas, v. 9, n. 1, p. 124-137, jan./abr. 1997.

LAKATOS, E. M.; MARCONI, M. de A. Fundamentos de metodologia científica. São Paulo: Atlas, 2010. 315 p. 
LIKERT, R. A technique for the measurement of attitudes. Archives of Psychology. v. 22, n. 140, p. 44-53, 1932. Disponível em: <http://psycnet.apa.org/psycinfo/1933-01885-001>. Acesso em: 03 jun 2015.

MILANO, M. C. D.; DAVOK, D. F. Consultor de informação: serviços prestados por empresas de consultoria nas áreas de biblioteconomia e gestão da informação. Revista ACB: Biblioteconomia em Santa Catarina, Florianópolis, v. 14, n. 1, p. 253-278, 2009. Disponível em: < http://revista.acbsc.org.br/racb/article/view/658>. Acesso em: 11 fev. 2015

MATHIAS, L. Biblioteconomia: um curso promissor que tem perfil jovem e profissionais gestores da informação. Notícias do dia. 2013. Disponível em: < http://ndonline.com.br/florianopolis/noticias/65243-biblioteconomia-um-curso-promissorque-tem-perfil-jovem-e-profissionais-gestores-da-informacao.html>. Acesso em: 14 jun. 2015.

MUELLER, S. P. M. Reflexões sobre a formação profissional para biblioteconomia e sua relação com as demais profissões da informação. Transinformação, Campinas, v. 1, n. 2, p. 175-185, maio/ago. 1989.

MUELLER, S. P. M. Uma profissão em evolução: profissionais da informação no Brasil sob a ótica de Abott - proposta de estudo. In: BAPTISTA, Sofia Galvão; MUELLER, Suzana Pinheiro Machado (Org.). Profissional da informação: o espaço de trabalho. Brasília: Thesaurus, 2004. p. 23-54.

PENA, A. de S. A evolução do mercado de trabalho formal do profissional da Informação no Brasil: um estudo a partir da RAIS/MTE, 1992-2005. 2007. 165 f. Dissertação (Mestrado em Ciência da Informação) -Universidade Federal de Minas Gerais. Belo Horizonte. 2007.

POLKE, A. M. A.; ARAÚJO, E. de M. B.; CESARINO, M. A. da N. Análise do mercado de trabalho do bibliotecário em Belo Horizonte. Revista da Escola de Biblioteconomia da UFMG, Belo Horizonte, v. 5, n. 2, set. 1976.

PASSARINHO, S. Taxa de desemprego no Brasil foi a mais alta em dois anos, diz IBGE. Jornal da Globo. Disponível em: <http://g1.globo.com/jornal-da-globo/noticia/2015/05/taxa-dedesemprego-no-brasil-foi-mais-alta-em-dois-anos-diz-ibge.html>. Acesso em: 14 jun. 2015.

RICHARDSON, R. J. et al. Pesquisa social: métodos e técnicas. 3. ed. São Paulo: Atlas. 2008. 334 p.

SILVA, E. L. da; CUNHA, M. V. da. A formação profissional no século XXI: desafios e dilemas. Ciência da Informação, Brasília, v. 31, n. 3, p. 77-82, set. /dez. 2002. Disponível em: <http://www.scielo.br/pdf/ci/v31n3/a08v31n3.pdf>. Acesso em: 14 jun. 2015.

UNIVERSIDADE DE SÃO PAULO. Informações sobre o curso de ciências da informação e da documentação,

[s.d].

Disponível

em: 
<http://www.ffclrp.usp.br/graduacoes/educacaoinformacaoecomunicacao/bachareladoembibli oteconomiaecienciasdainformacaoedadocumentacao.php>. Acesso em: 18 jan. 2015.

VALENTIM, M. L. P. O moderno profissional da informação: formação e perspectiva profissional. Encontros-Bibli: revista eletrônica de Biblioteconomia e Ciência da Informação, n. 9, jun. 2000. Disponível em: <http://www.encontrosbibli.ufsc.br>. Acesso em: 18 ago. 2014.

WALTER, M. T. M. T. Bibliotecários no Brasil: representações da profissão. 2008. 345 f. Tese (Doutorado em Ciência da Informação) -Universidade de Brasília, Brasília, 2008. Disponível em: $<$ http://bdtd.bce.unb.br/tedesimplificado/tde_busca/arquivo.php?codArquivo=4037>. Acesso em: 15 abr 2015.

Recebido/Recibido/Received: 2016-06-21

Aceitado/Aceptado/Accepted: 2016-07-18 